\title{
Exploring on Gender Perception in eSports Gamers
}

\author{
Jinhee $\mathrm{Kim}^{1}$ and Dayoun $\mathrm{Lim}^{2} *$ \\ ${ }^{1}$ Department of Content Convergence, Andong National University, Andong, Korea \\ ${ }^{2}$ Department of Sports and Leisure Studies, Fareast University, Eumseong, Korea
}

\begin{abstract}
[Purpose] The purpose of this study is to investigate gender perception of eSports gamers. [Methods] 8 male gamers in the professional team were selected purposeful and snowball sampling. Data were collected through face-to-face and online interviews, and analyzed by content analysis and classification analysis. [Results] Esport gamers explained their indirect experiences with female gamers. The results are as follows. First, it was confirmed that the number of female gamers was small and they had a negative stigma image, and this consistently reproduced the gender role stereotype of female gamers in digital games. Second, in the game world, men are swearing, verbal abuse, and sexual harassment against female gamers, which suggests that female gamers are viewed as targets of sexual play from the perspective of the strongest. Third, eSports male gamers are characterized by being conservative or open to gender perceptions by age. We discussed what to need in eSports which is male dominated area should give to opportunity for equality education. [Conclusions] In-depth understanding of gender perception in e-sports players should be prioritized in order to change gender perception. Therefore, it would be an important research topic bring to discuss. This paper is expected to be a beneficial material for eSports gender studies and stimulate to discuss gender imbalance.
\end{abstract}

Key words: eSport, Gender perception, Stereotype, Sexual harassment, gender equality.

\section{서 론}

글로벌 게임 산업 분석 회사인 뉴주(Newzoo)는 2021년 에 주목할 e스포츠 동향으로 $\mathrm{e}$ 스포츠가 기존의 스포츠 구조 에서 라이프스타일 브랜드로 콘텐츠를 확장하여 대중문화 로 진입하기 위해 다양화를 꾀할 것이라 했다. 소비자의 욕 구가 컴퓨터 게임에서 모바일 게임으로 이동하면서 전통 스 포츠 구단이 e스포츠 투자를 확장할 것으로 기대하고 있다 (Newzoo, 2021). 이미 뉴욕 양키스, 파리생제르맹 구단들 이 e스포츠팀을 창단했고, 중앙대, 버클리대학 등 국내 및

논문 투고일 : 2021.02.02.

논문 수정일 : 2021.03.17.

게재 확정일 : 2021.04.06.

* 교신저자 : 임다연(dylim84@kdu.ac.kr)
해외 대학들도 $\mathrm{e}$ 스포츠과를 만들거나 $\mathrm{e}$ 스포츠선수들을 특 기생으로 활용하고 있다. 또한 $\mathrm{e}$ 스포츠 남녀 선수의 학습에 대한 태도와 $\mathrm{e}$ 스포츠 참여 동기 수준 간에 긍정적인 인과관 계가 있다는 연구 결과는 고무적이다(Bayrak, 2020).

세계적으로 바이러스를 무기로 전쟁을 치르고 있는 팬데 믹 상황이 1년 이상 지속되면서 가장 두드러진 사회 현상 중 하나는 재택근무, 실시간 화상 회의, 게임 및 영화관람 등 온 라인 활용이라 할 수 있다. 특히, 온라인 게임인 e스포츠의 성장이 눈에 띈다. 산업측면에서 일컫는 게임시장은 2020년 기준으로 전년대비 $9.3 \%$ 증가한 매출을 기록하였다 (Newzoo, 2020). 학문적으로는 전통적인 스포츠의 제도 화, 경쟁성, 기술 등을 갖고 있으므로 $\mathrm{e}$ 스포츠를 정식 스포츠 로 인정하고 있는 점을 꼽을 수 있다(Park, 2020; Lee \& Kim, 2020; Cunningham et al., 2018). 스포츠 종목으로 서의 대중성은 e스포츠가 가장 빠른 속도로 발전하고 있으 
며, 큰 인기를 누리고 있다(Park et al., 2020), 이를 증명하 듯 e스포츠는 2022년 항저우 아시안게임에 정식 종목으로 채택되었다.

이처럼 빠른 속도와 더불어 눈부신 성장을 보이는 $\mathrm{e}$ 스포 츠계지만 젠더불평등 문제는 사회에서 전통스포츠보다 극심 하게 발생하고 있다(Maeng, et al, 2018; Song, et al. 2017). e스포츠 특성상 직접 대면하지 않고, 스크린 안에서 이루어지므로 무차별적인 언어폭력과 혐오, 차별이 즉각적 으로 빠르게, 여럿이 가담하여 집단적으로 일어나고 있는 점 이다(Kim, 2019). 이로 인해 여성 게이머들이 성희롱에 시 달리고 있으며, 정상급 여성 선수임에도 불구하고 수입은 남 성 선수의 $10 \%$ 도 채 미치지 못하는 수입 등 성차별이 극명하 다. 격투 스포츠 종목과 달리 남성 선수가 가진 신체적 이점 이 두드러지지 않는 $\mathrm{e}$ 스포츠계에서 여전히 여성 선수들이 극 소수인 점을 지적하기도 했다(Kim, 2016.11.21). 퓨리서치 센터 조사에 따르면 자신이 "게임을 한다"고 표현하는 비율은 남성과 여성이 거의 차이가 없었지만, 자신을 '게이머'라고 표현하는 비율은 남성이 여성의 2 배에 달했다는 점에서 e스 포츠에 대한 남녀 간 인식차이는 크다고 볼 수 있다(Kim, 2016.11.21). '온라인 게임 내 성차별, 성희롱 실태조사'에 따르면 여성게이머의 $91.2 \%$ 가 성차별 또는 성희롱의 피해를 당하였다(Korea creative content agency, 2017).

국내만의 문제는 아니다. 해외에서 실시한 온라인 게임 내 성차별 조사에서는 여성 게이머의 64\%가 성차별을 받았 다고 응답하였다(Kim et al., 2019; Vitis L \& Gilmour F, 2016; Brehm A, 2013). 여성 게임단 ‘UBINITED’를 설립 한 정상급 여성 게이머이자 2014년 영향력 있는 30인에 이 름을 올렸던 스테파니 하비는 $\mathrm{e}$ 스포츠계에 여성 선수의 비 율은 $5 \%$ 밖에 되지 않고 성 고정관념이 따라다닌다고 했다 (Kim, 2014.01.08). 그녀는 여성이기 때문에 e스포츠에 몸담으면 안 된다는 이유로 성폭력 위협을 많이 받는다고 말 했다. 'Counter Strike: Global Offensive' 대회 여성부에 서 우승한 '시크릿 팀' 은 "남성 선수들은 여성 선수들과의 경 쟁을 번외경기 정도로 본다"며 성차별 경험을 토로했다 (Kim, 2016.11.21). 여성 전용 대회가 있지만 이러한 분류 가 $\mathrm{e}$ 스포츠에서 성별을 가르는 풍토를 굳힐 수 있어 논란의 대상이 되기도 하며, 여성 대회는 남녀 수입 격차를 크게 늘 리는 직접적인 요인이 되고 있다. 프로스포츠에서도 발생하 는 문제 중 하나는 여성부 경기의 중계방송 수가 크게 차이 나고, 여성 선수나 팀의 후원사 등이 훨씬 적기 때문에 수입
의 격차가 나는데, e스포츠에서는 더욱 두드러지게 나타난 다. 정상급 남성 선수들의 수입은 250만 달러(약 29억6천 만 원)지만 여성 정상급 선수들은 20만 달러(약 2억4천 만 원) 수준이다(Kim, 2016.11.21.).

이상과 같은 현상과 문제의식을 갖고 본 연구는 $\mathrm{e}$ 스포츠 현장에 잠재되어 있는 젠더인식을 탐색해보고자 한다. 이를 통해 온라인 게임 강국이면서 대중 인기도가 높은 한국 e스 포츠에서 젠더의 구조와 현상에 대한 학문적 관심과 연구 활 동의 필요성을 환기시키는 기초자료를 제공하고자 한다. 나 아가 점차 확산될 $\mathrm{e}$ 스포츠를 위해 젠더 및 성 평등에 필요한 교육적 시사점을 살펴본다. 이를 위해 본 연구는 첫째, 한국 $\mathrm{e}$ 스포츠의 젠더 현상을 미디어 사례를 통해 살펴본다. 둘째, $\mathrm{e}$ 스포츠선수들이 지각하는 젠더인식은 무엇인지 파악한다. 사회현상으로서 미디어에 드러난 $\mathrm{e}$ 스포츠의 젠더와 관련한 사례를 살펴보는 것은 e스포츠에 잠재되어 있는 문화적 인식 을 살펴보는데 기초자료가 될 것이며, 현재 활동 중인 e스포 츠선수의 인식을 파악하는 것은 개인적 인식을 살펴보는데 도움이 될 것이다. 이를 통해 e스포츠에서 발생하는 젠더 문 제를 해결하는데 촉매제 역할을 할 수 있을 것으로 기대한다.

\section{연구방법}

\section{참여자}

이 연구의 참여자는 현재 $\mathrm{e}$ 스포츠 프로선수로 활동하고 있는 8명을 목적표집과 눈덩이 표집으로 섭외하였다. 연구 참여에 동의하였으며, 참여자의 개인적 특성은 〈Table 1〉 과 같다. 본 연구는 남성 e스포츠선수가 현장에서 젠더 관련 여성 $\mathrm{e}$ 스포츠 선수와의 직, 간접적 경험이 있는 사례를 살펴 보기 위해 다중사례방법(multi case research)으로 수행하 였다. e스포츠선수의 젠더 감수성은 어떠한지, 여성 선수와 의 직, 간접적 경험을 통해 자신의 젠더 인식을 탐구하는 데 적절한 연구방법이다(Yin, 2009).

참여자는 남성으로 대부분 20대이며 10년 정도 선수경 력을 갖고 있다. 연령과 경력을 감안하더라도 고액의 연봉 을 받고 있다. 게임종목별로 연봉 차이가 크다. 국내 e스포 츠선수들의 평균 연봉은 1 억7000만원으로 엄청난 돈을 벌 지만, 평균 은퇴 나이는 26.1세로 매우 이른 편이다(Noh, 
Table 1. Participants

\begin{tabular}{ccccccc}
\hline \hline $\begin{array}{c}\text { Na } \\
\text { me }\end{array}$ & eSport & $\begin{array}{c}\text { Gen Length } \\
\text { der of career }\end{array}$ & Age & $\begin{array}{c}\text { education } \\
\text { background }\end{array}$ & $\begin{array}{c}\text { annual } \\
\text { income } \\
\text { (million) }\end{array}$ \\
\hline A & Starcraft2 & M & 14year & 29 & $\begin{array}{c}\text { middle school } \\
\text { graduate }\end{array}$ & 300 \\
\hline B & Kartrider & M & 9year & 21 & $\begin{array}{c}\text { high school } \\
\text { graduate }\end{array}$ & 10 \\
\hline $\mathrm{C}$ & Kartrider & M & $\begin{array}{c}\text { 7year } \\
\text { 6month }\end{array}$ & 22 & $\begin{array}{c}\text { high school } \\
\text { graduate }\end{array}$ & 12 \\
\hline $\mathrm{D}$ & Starcraft2 & $\mathrm{M}$ & $\begin{array}{c}\text { 8year } \\
\text { 6month }\end{array}$ & 21 & $\begin{array}{c}\text { high school } \\
\text { graduate }\end{array}$ & 90 \\
\hline $\mathrm{E}$ & Kartrider & $\mathrm{M}$ & $\begin{array}{c}\text { 11year } \\
\text { 6month }\end{array}$ & 22 & $\begin{array}{c}\text { high school } \\
\text { graduate }\end{array}$ & 8 \\
\hline $\mathrm{F}$ & Tekken & $\mathrm{M}$ & 16year & 31 & college graduate & 600 \\
\hline $\mathrm{G}$ & $\begin{array}{c}\text { Battlegrou } \\
\text { nds }\end{array}$ & $\mathrm{M}$ & $\begin{array}{c}\text { 10year } \\
\text { 8month }\end{array}$ & 24 & $\begin{array}{c}\text { high school } \\
\text { graduate }\end{array}$ & 60 \\
\hline $\mathrm{H}$ & $\begin{array}{c}\text { League of } \\
\text { Legends }\end{array}$ & $\mathrm{M}$ & 6year & 21 & $\begin{array}{c}\text { high school } \\
\text { graduate }\end{array}$ & 150 \\
\hline \hline & & & & &
\end{tabular}

2019.12.05). 한국콘텐츠진흥원에 따르면 2019년 기준 국 내 e스포츠 프로선수는 약 420 명이고, 평균 연령은 20.2세, 연습생은 17.4 세다. 재능 있는 선수들은 대개 중학교 때 발 탁되어 육성 군에 들어가고, 고등학생부터 프로 생활을 시 작한다. 전체 프로 선수 중 33\%가 17-19세이다(e-Sports academy Korea, 2019). 본 연구의 참여자는 e스포츠 프 로선수로 활동하고 있으므로 젠더 인식에 대한 선수의 전형 성(typical)을 살펴보는 데 있다.

\section{자료 수집 및 분석}

본 연구의 자료수집 기간은 2020년 1월초부터 3월말, 9-10월, 2회에 걸쳐 선수와의 직접 인터뷰를 통해 수집하 였다. 코로나바이러스로 인해 대면을 계획하였으나 방역 상 황으로 변경되거나, 선수들의 대회참가 등의 일정에 맞추어 자료수집 기간과 방법이 조정되기도 하였다. 인터뷰 조사도 구는 질문지를 활용하였다. 참여자의 요청으로 질문지를 메 일로 보냈으며, 직접면담은 개인별로 진행하였다. 면담횟수 는 참여자 각 1 2회씩이며 대화를 나눈 시간은 1시간 3시 간 정도 소요되었다. 질문지는 연구진의 협의를 통해 $\mathrm{e}$ 스포 츠선수들의 젠더 인식을 파악할 수 있는지에 필요한 구조화 (structured) 질문과 개방형(open-ended) 질문을 혼합하
여 구성하였다. 질문지의 내용 구성은 첫째, 여성 $\mathrm{e}$ 스포츠선 수에 대한 생각과 경험, 둘째, 여성 e스포츠선수에 대한 태 도와 e스포츠계에 미치는 영향을 포함하였다. 참여자들의 동의로 모든 면담은 녹음하였고, 컴퓨터를 이용하여 전사한 분량은 19 매였다.

자료 분석은 반복적으로 사용한 단어나 문구들을 분류하는 체계적 분류분석과 항시비교법으로 분석하였다. 체계적 분 류분석과정은 첫째, 사실, 현상, 경험, 개념 등의 설명을 위해 사용한 단어들을 활용해 젠더인식에 대한 인과관계를 파악하 였다. 둘째, 진술한 내용에서 의미 있는 문장이나 문구로부터 유사한 의미들을 상호관계성에 따라 일관성 있는 진술로 통 합하여 주제(theme)를 도출하였다. 셋째, 도출된 주제의 속 성들을 문헌자료 및 면담자료와의 비교분석을 통해 젠더에 대한 e스포츠선수의 인식을 주요 쟁점별로 범주화하였다.

\section{$\mathrm{e}$ 스포츠에서의 젠더 구조와 현상}

$\mathrm{e}$ 스포츠선수의 젠더 인식에 대한 이론적 토대를 살펴보 기 위해 최근에 일어난 각종 사례와 뉴스 등 미디어 자료를 검토하였다. e스포츠를 주제로 한 선행연구들은 문헌을 통 한 e스포츠의 개념과 역사(Lee \& Hwang, 2020; Lee, 2020), 스포츠로서의 정당성(Park, 2020: Lee \& Kim, 2020), e스포츠선수의 약물복용 문제(Park et al., 2020), 실증조사를 통한 e스포츠 참여현황과 만족도 분석 등이다 (Kim \& Hwang, 2020; Joo \& Yoo, 2019). 따라서 본 연 구는 기존에 수행된 연구내용이 e스포츠에서의 젠더 인식 을 파악하는 데 부족하다고 판단하여 최근 미디어 자료를 통 해 e스포츠에서의 젠더 '현실 문제'를 살펴보았다.

2000년대 한국 e스포츠의 대표 게임이 블리자드의 '스 타크래프트'였다면, 2010년 이후 한국 e스포츠의 대표적인 게임은 라이엇게임즈의 '리그 오브 레전드'(이하 LoL)이다 (Seong, 2019.07.07). 스타크래프트 후속작으로 출시된 ‘스타크래프트 2'의 e스포츠 리그가 승부조작, 계약위반 등 비윤리적인 사건사고에 휘말려 위기에 처했다. 이 때 리그 오브레전드(LoL)가 출시되며 큰 인기를 끌었고, e스포츠의 성장에 큰 몫을 하게 되었다. LoL은 특히 한국에서 큰 인기 를 얻었고, 현재까지 페이커 등 세계적인 선수들을 배출해 내고 있다. 한국에서 더욱 인기를 끌 수 있었던 요소 중 하나 는 팀을 이뤄 플레이를 해야 하는 룰을 가지고 있기 때문에 
친구와 함께 $\mathrm{PC}$ 방에 가서 여럿이 게임을 하는 것이 청소년 문화로 있는 우리나라에 적합한 듯 보인다(Lee, 2019; Joo \& Yoo, 2019).

LoL의 위세에 블리자드의 '오버워치', 카카오게임의 '배 틀그라운드' 등이 계속 도전하고 있지만 여전히 한국 PC방
게임 순위 1위는 LoL이다(Seong, 2019.07.07). 그러나 e 스포츠의 인기 속에 급격한 성장과 더불어 불미스러운 사 건·사고는 지속적으로 발생 하였다. 〈Table 2〉는 2010년 부터 2020년까지 약 10 년간 e스포츠에서 발생한 주요 사 건·사고 내용이다.

Table 2. eSport Incident category

\begin{tabular}{|c|c|c|c|}
\hline & Category & Incident & Year \\
\hline \multirow{7}{*}{$\begin{array}{l}\text { Gender } \\
\text { Issues }\end{array}$} & \multirow{2}{*}{$\begin{array}{l}\text { Gender } \\
\text { discrimination }\end{array}$} & Overwatch Female professional gamer "게구리" Demonstration of public ability & 2017 \\
\hline & & $\begin{array}{l}\text { Starcraft Female professional gamer "Seo Jisoo" } \\
\text { The image of a player is a female player who is "right to lose." }\end{array}$ & 2007 \\
\hline & \multirow{3}{*}{$\begin{array}{c}\text { Sexual } \\
\text { harassment } \\
\text { (Language) }\end{array}$} & $\begin{array}{l}\text { DC Inside at the League of Legend Gallery, The term "hyeji" } \\
\text { appears as a slang for "unskilled female gamer." }\end{array}$ & 2018 \\
\hline & & YouTube Ranking show Program Progress Announcer "This is all Hyeji” Remarks & 2019 \\
\hline & & $\begin{array}{l}\text { In Overwatch, the female character "Mersi" and the slang term "Borsi" were combined } \\
\text { to refer to a female gamer who only follows her around doing nothing. }\end{array}$ & 2016 \\
\hline & $\begin{array}{c}\text { Sexual } \\
\text { harassment } \\
\text { (Body) }\end{array}$ & Overwatch Gamer "Free" sexual harassment against minors & 2021 \\
\hline & sexual assault & $\begin{array}{l}\text { League of Legend "Pimir Incident" } \\
\text { A match-fixing fighter's attempt to commit sexual assault. }\end{array}$ & 2014 \\
\hline \multirow{10}{*}{$\begin{array}{l}\text { Social } \\
\text { Issues }\end{array}$} & \multirow{7}{*}{ match fixing } & $\begin{array}{l}\text { E-Sports 09-10 Shinhan Bank's professional league } \\
\text { has been involved in a match-fixing scandal. }\end{array}$ & 2010 \\
\hline & & Unfair judgment due to power outage & 2010 \\
\hline & & StarCraft Warcraft $3<$ Map Manipulation Incident $>$ & 2012 \\
\hline & & StarCraft 2 match fixing incident & 2015 \\
\hline & & Overwatch's APEX Challengers accused of match fixing & 2017 \\
\hline & & $\begin{array}{l}\text { League of Legend "Pimir Incident" } \\
\text { A match-fixing fighter's Suicide attempt }\end{array}$ & 2014 \\
\hline & & G-Star Starcraft match fixing & 2018 \\
\hline & \multirow{3}{*}{$\begin{array}{l}\text { breach of } \\
\text { contract }\end{array}$} & League of Legend $<$ Kanabi Incident $>$ & 2019 \\
\hline & & E-sports coach assault & 2020 \\
\hline & & E-Sports Association's public goods statement controversy & 2010 \\
\hline
\end{tabular}


국내 e스포츠의 비윤리적인 사건·사고는 크게 젠더 이 슈와 사회적 이슈로 나눌 수 있다. $\mathrm{e}$ 스포츠에서 발생한 젠 더이슈는 성차별, 혐오표현, 성희롱, 성폭행으로 나눌 수 있다. 다른 분야 보다 독특한 점은, $\mathrm{e}$ 스포츠에서만 다뤄지 고 있는 혐오표현이다. “혜지”, "보르시”, "여왕벌” 등 여성 게이머를 비하하는 혐오표현들이다. 2016년 오버워치 내 에 여성캐릭터로 실제 여성유저들이 많이 선택하는 캐릭 터 '메르시'와 여성의 생식기를 일컫는 비속어가 합쳐져 ‘보르시'라는 표현이 등장하여 게임 도중 채팅창을 뜨겁게 달구기도 하였다. 이후 오버워치 내에서 금지어로 선정되 기도 하였으나 여전히 인터넷 사이트 등에서는 계속해서 회자되고 있는 혐오표현 중 하나이다. 또한 디시인사이드 리그오브레전드 갤러리에서 '실력이 없는 여성게이머'를 지칭하는 속어로 “혜지”라는 표현이 등장하였는데, 2019 년 LOL유튜브 랭킹쇼들이 실제 경기 시 성능이 미묘하다 는 이유로 "이거 다 혜지"라는 발언을 해 해당영상이 삭제 되는 등의 논란이 또 한 차례 불거졌다(Seong, 2019.07.07).

$\mathrm{e}$ 스포츠에서는 성차별의 사례도 볼 수 있다. 스타크래 프트에서 임요한 다음으로 인기를 얻었던 서지수 선수는 뛰어난 실력으로 연승을 거두었으나, '지는 것이 당연한 여자 선수'로 인식되며, 서지수 선수에게 지는 남성 프로 게이머는 이변으로 여겨졌고, 한동안 조롱을 피하지 못하 는 상황까지 이어졌다. 오버워치 리그의 유일한 여성 선수 이자 차세대 리더 10 인에 올랐던 게구리 선수는 여성 프로 게이머 임에도 불구하고 실력이 좋다는 이유로 경기에서 핵사용을 의심받기도 하였으며, 이러한 부정행위 의심을 해명하기 위해 공개적으로 실력을 입증하는 절차를 거쳤 다. 그럼에도 불구하고 공개적으로 실력을 입증하기 전 게 구리 선수에게 혐오발언과 협박을 남긴 가해자들은 행동 을 반성하거나 사과하지 않았다(Seong, 2019.07.07). 이 는 '프로게이머'라는 한정된 영역에서 그치지 않는다. 앞 서 문제가 되었던 '혜지'가 여성 게이머를 부르는 별칭인 것처럼, 이미 오래 전부터 게임 커뮤니티 내부에서 여성 게 이머에 대한 취급은 고정관념을 넘어 언어 폭력으로 혐오 를 보편화하고 있다(Seong, 2019.07.07).

사회적 이슈로는 승부조작과 불공정계약으로 나눌 수 있는데, 불공정계약의 경우 2019년 리그오브레전드 "카 나비사건”과 2020년에 발생한 e스포츠구단의 감독이 선 수를 폭행했던 사건이 발생하였다. "카나비사건"은 희대
의 e스포츠 노예계약 실태가 밝혀진 사건으로, 미성년자였 던 조규남(유저명 카나비)선수에게 불공정 노예계약을 일 삼으며 여러 차례 협박이 이루어진 것이 밝혀져 e스포츠팬 들의 분노를 불러일으켰던 사건이었다. 또한 2020년에는 씨맥에 김대호 그리핀 감독이 최성원(유저명 소드)선수에 게 수차례 폭행과 폭언을 한 것이 밝혀져 논란이 되었다.

$\mathrm{e}$ 스포츠의 근간을 흔들어놓았던 승부조작 사건을 빼놓 을 수 없다. $\mathrm{e}$ 스포츠에서 첫 승부조작 사건으로 많은 팬들 에게 충격을 안겼던 09-10신한은행 프로리그 승부조작사 건은 스타크래프트 리그에서 스타크래프트 서버 클랜 운 영자와 그 친구인 조직폭력배 김모씨, 현역 축구선수 정명 호 등 브로커들의 주도로 마재윤과 원종서 등 전·현직 프 로게이머 11 명이 매수돼 대규모의 승부조작을 일삼아온 사실이 적발된 것이다. 같은 해, 네이트 MSL결승전에서 발생한 정전으로 인해 결승전 진행 중 선수들의 컴퓨터가 다운되었고 재경기가 아닌 우세승을 처리하며 논란이 커 졌다.

2012년에는 스타크래프트 워크래프트3 맵 조작 사건 으로, 많은 e스포츠선수들의 분노를 일으켰는데 그 주인공 은 그 당시 $\mathrm{MBC}$ 게임의 해설위원 장재영이었다. 장재영은 상대적으로 약체 종족이 강한 종족을 이겨 승리하는 극적 인 상황을 일으켜 리그를 흥행시키려는 목적으로 은밀하 게 경기에서 사용하는 맵을 조작하였다 $(\mathrm{Kim}$, 2005.03.02). 실제 경기를 하던 선수들이 이상하게 여겨 맵이 조작되었음이 밝혀졌다. 2014년에는 천민기(유저명 피미르)선수가 자신의 팀에 노대철 감독의 승부조작을 도 왔다는 글을 작성한 직후 자살을 시도한 사건이 발생하였 다(Online issue team, 2014.03.31). 다행히 피미르 선 수는 회복을 해 많은 팬들의 응원을 받게 되었다. 큰 사건 이 연이어 발생했지만 $\mathrm{e}$ 스포츠의 승부조작은 그칠 줄 몰랐 다. 2015년 또 한 차례 스타크래프트2에서 감독과 선수 등 총 11명이 승부조작 사건 혐의가 밝혀졌고, 2017년에는 오버워치 APEX 챌린저스 에서 승부조작을 시도한 감독과 선수가 불구속 입건되었다. 그리고 지스타 스타크래프트 대회에서 승부조작 혐의가 2018년에 드러나기도 하였다. 뜨거운 인기에 힘입어 타 종목보다 급성장을 일궈낸 e스포 츠에서 비윤리적인 사건·사고가 꾸준히 발생하고 있어 이 에 대한 대비책이 요구되는 실정이다. 무엇보다 $\mathrm{e}$ 스포츠에 서의 여성 혐오 관련 문제는 심각하다. 앞서 언급했던 승부 조작 사건의 피미르 선수가 자살시도를 하기 전, '어차피 
죽을 것'이라고 생각하며 투신시도 전 한 여성을 성폭행 한 사례가 뒤늦게 밝혀져 사회에 충격을 주었다. 또한 2021 년 미성년자 성추행 혐의로 구속된 오버워치 윤태인 선수 가 실형을 선고받으며 선수계약이 해지되는 사건이 발생 한 바 있다.

이 같은 사건들은 기존 스포츠와는 다른 형태의 젠더관 련 사건으로, e스포츠의 젠더 구조와 현상을 살펴볼 수 있 었다. e스포츠의 젠더 이슈는 첫째, $\mathrm{e}$ 스포츠종목에서만 사 용되는 여성혐오 표현이 내재되어 있다. 이는 보이지 않는 공간인 온라인에서 대결하는 종목 특성에 따라 쉽게 여성 을 비하하거나 혐오하는 것으로 나타났다. 둘째, 성차별이 빈번하게 나타나고 있다. 기존 스포츠에서의 성차별과 e스 포츠에서의 성차별은 친밀하고 은밀한 언어폭력과 성추행 의 특성을 갖고 있다. 기존 스포츠의 경우 대표적인 성차별 은 남녀 선수 연봉 차이, 경기력 차이, 프로스포츠 경우 관 중의 수 차이다(Kang, 2000). 그러나 e스포츠에서의 성 차별은 여성 게이머에 대한 낮은 게임실력의 부정적 이미 지 인식으로부터 낙인찍기 시작하여 게임수행에 관한 일 방적 비난과 언어폭력을 보이고 있다.

\section{$\mathrm{e}$ 스포츠선수의 젠더 인식 결과}

참여자들의 인터뷰 자료를 분석한 결과 남성 $\mathrm{e}$ 스포츠 선 수들은 여성 게이머와의 직접적인 경험은 없고, 간접적인 경 험을 갖고 있다. 즉, 여성 게이머와 실제로 게임을 하지 않고 여성 게이머에 대해 듣거나 $\mathrm{TV}$ 를 통해 대회에 참가한 여성 선수를 본 정도이다. 연구 참여자들의 근거 자료는 남성 $\mathrm{e}$ 스 포츠선수들이 갖고 있는 여성 게이머에 대한 인식 사례에 해 당한다. e스포츠선수의 젠더 인식을 분석한 개념은 〈Table $3>$ 과 같다. 참여자들은 자신이 간접적으로 경험한 여성 게이 머에 대한 부정적인 인식이 만연해 있었다. 여성 게이머의 수 가 적고, 유저명이 여성스러움으로 인해 이미 여성의 실력이 없어, 게임을 망하게 한다는 편견을 갖고 있는 것으로 확인되 었다. 상위범주로 도출한 여성 게이머에 대한 성역할 고정관 념은 이러한 여성에 대한 차별적 근거들이 남성 게이머들의 보편적 인식을 공고하게 만들고 있으며, 여성 게이머로 인지 한 다음부터는 게임에서의 성희롱과 성적 괴롭힘 정도는 문 제될 것 없다는 것으로 여성 게이머를 강자의 성적 유희대상 으로 보고 있다.

Table 3. Results of classification analysis of gender perception in eSports gamers

\begin{tabular}{|c|c|c|}
\hline Content & Lower Category & Upper Category \\
\hline Ignored due to low number of female gamers & \multirow{7}{*}{$\begin{array}{l}\text { Strengthen awareness of } \\
\text { female gamers through } \\
\text { gender discrimination. }\end{array}$} & \multirow{7}{*}{$\begin{array}{c}\text { Reproducing gender } \\
\text { stereotypes about female } \\
\text { gamers }\end{array}$} \\
\hline Being discriminated against in the game for being a woman & & \\
\hline The role of women is to be viewed as spectators and visitors. & & \\
\hline When a man says he's playing games, he's branded, but even worse by a woman. & & \\
\hline sexiness about user names and characters (Scarlett, Madonna) & & \\
\hline $\begin{array}{l}\text { Do not distort or acknowledge the skills of female users (using proxy games, } \\
\text { buses and nuclear weapons). }\end{array}$ & & \\
\hline Female users lose no matter what. & & \\
\hline sexual harassment, verbal abuse, and lewdness. & \multirow{4}{*}{$\begin{array}{l}\text { sexual harassment and } \\
\text { sexual harassment in the } \\
\text { game. }\end{array}$} & \multirow{4}{*}{$\begin{array}{l}\text { Strong man's sexual } \\
\text { entertainment }\end{array}$} \\
\hline Sexual harassment with female users & & \\
\hline Making fun of yourself in the chatroom when playing games & & \\
\hline Male gamers are collectively and repeatedly loathsome. & & \\
\hline $\begin{array}{l}\text { It would be different if there were schools and businesses that raised women } \\
\text { who liked to play games. }\end{array}$ & \multirow{2}{*}{$\begin{array}{l}\text { Attitudes toward e-sports } \\
\text { women }\end{array}$} & \multirow{2}{*}{ Role of e-sports } \\
\hline It'll be different if you make a lot of games that couples play. & & \\
\hline
\end{tabular}


제가 다른 종목에는 크게 관심이 없어서 잘 모르겠는데, 예전에 스 타크래프트에 여자 선수가 2-3분이 있었던 것 같고, 현재 제 종목 인 롤에서는 제가 알기로는 없는 걸로 알고 있어요. $(\mathrm{H})$

철권은 국내에서 활동하시는 분이 10 명 미만이에요. 아무래도 여 자가 e스포츠를 하면 '여자가 무슨 게임이냐' 이런 인식도 있는 것 같고, 여자들은 보통 어릴 때 별로 관심이 없지 않나요. (F)

제가 초기 스타크래프트부터 대회에 나오면서 활동한 여성이 있었 어요. 몇 년 전에 한국 프로 여자선수 1 명 있었는데, 지금은 중국에 서 활동하고 있어요. 여기는 여자 프로팀이 없으니까요. (A)

\section{여성 게이머에 대한 고정관념 재현: 너희는 약자와 들러리야}

$\mathrm{e}$ 스포츠선수들이 인식하고 있는 여성 게이머의 젠더관 련 경험은 수적으로 소수인 여성 게이머들의 활동이라 게임 실력에 대해 정당하게 평가나 인정받기 보다는 이미 사회에 서 형성된 여성에 대한 편견과 표면적으로 부정적인 인식이 내재화 되어 있는 경험들이 포함되어 있었다. 더불어 자신 은 여성 게이머를 디지털 세계에서 대할 때 고정관념을 드러 내지는 않았으며 다른 이들의 행위를 목격한 것에 그친다는 점을 강조하고 있다. 이를 통해 e스포츠 남성 선수들은 여성 게이머의 경험이 타인을 통해 형성된 것이며, '없다'라고 확 증하는 언어사용과 '잘 모르겠다'는 중립적인 입장과 ' 같 아요', ' 편이다' 등으로 표현하여 자신은 그러한 정보를 기 억해내는 재현자라는 것이다.

세계적으로 게임을 즐기거나선수로 활동하는사람이 남자가더 많잖아 요 물론 여성 중에도 뛰어난 분들이 있지만 비율도 상당히 적은편이고, 최근게임들이 여럿이 하는 팀 게임이기 때문에다같이합숙을 해야하 는 것도 여성에게 현실적으로 큰 장애물이 되지 않을까 생각해요. $(\mathrm{G})$

카트라이더에서는 여자가게임을 잘하는 것을 본적이 없습니다. (B) 실 제로 카트라이더에 여성 프로게이머도 과거에 존재했고, 프로는 아니지 만 현재 잘하는 여성 유저 분들도 존재하기 때문에 잘 모르겠어요. (D)

게임은 주로 '남자가잘한다, '남자가많이한다'라는 남자가 일반화가 되어 여자가 하는 것에는 특별하게 생각하는 경우가 있어서 그렇게 생 각해요. (E)

$\mathrm{e}$ 스포츠선수들은 여성 게이머를 타자의 입장에서 동일 화하고 있는 젠더 인식을 갖고 있다. 흔히 타자를 대변할 때
공간과 입장에 일정한 거리를 둔다는 점에서, 자신은 그 안 에 있는 대상(남성이라는 집단)이지만 동시에 타인으로서 정체화된 타자(identified other)는 아니라는 점이다. e스 포츠선수에게 형성된 여성 게이머에 대한 젠더 인식은 연령 에 따라 차이가 있는 것으로 보인다. 남성은 어렸을 때부터 $\mathrm{PC}$ 방 출입이 자유롭고 승부욕이 강하므로 집단으로 하는 팀 게임에서의 역할을 잘 알고 있다는 사회적으로 형성된 학 습의 경험이 20대 후반 선수의 인식에 해당된다. 20 대 초반 선수들은 중립적인 입장이거나 우호적인 생각을 갖고 있는 점이 특이하다.

남자는 어릴 적부터 친구들이랑게임하거나 $P C$ 방가거나 좋아하는 사 람들이 많아서 접근성이 수월하다고 생각합니다. e스포츠도 10대부 터 즐기다보니까 여성들이 게임에 관심도도 낮지 않을까 싶다. 게임 자체가남성들이더 많이즐기는 여가생활이고 남성들은 특유의승부 욕이나 자존심 때문에 하드 유저가 많이 발생하나, 여성 유저들은 대 체로 가벼운 여가 정도로 라이트하게 즐기는 경우가 휠씬 많아요. (A)

윗세대부터 기성세대들이 여자의 사회적 활동을 억압하는 환경이었 다고 생각하는데요. (예를 들면 여자가 운전하면 살림이나 하라는 그 런 시선들) 그러다보니 다음 세대들도 그런 시선을 자연스럽게 답습 해서 여자들에게 그대로 표출하곤 해요. 그리고 외모지상주의가 있 고사회적으로도 그런 분위기가 전반적으로 깔려있어 게임 실력보다 는 여자의 외모를 먼저 품평을 하는 게 있고요, 여자가 남자보다 게임 을 못한다는 선입견이 있어 여자가 게임할 경우 무시하거나 조롱하 는 경우가 많아요. 여성을 게임 상에서 만날 경우 약자로 생각하는 경 우가 많은 것 같습니다. (F)

‘게임 중독'이란 단어 때문에 인식이 부정적으로 고착화 된 거같습니 다. 저희 어머니도 좋지 않은 편견으로 저를 보셨는데 막상 하고나니 까어머니가 저보다 더 열정적으로 봐주시고 응원해주셨습니다. $(\mathrm{H})$

여성 남성 따지지 않고 누구나 게임을 즐겨할 수 있다고 생각합니다. 게임을 즐겨하는 사람과 선수를 꿈꾸고 하는 사람은 게임에 대한 이 해도와 생각도 달라진다고 생각합니다. 그 점에서 목표가 있고 없고 이런 불편한 시선과 사회적 편견이 있지 않을까 생각합니다. (G)

$\mathrm{e}$ 스포츠에 관심이 있거나 좋아하는 여성에 대해 불편한시선이나 편 견 같은 건 없는 것같아요. 그러나 보통 유명한 $\mathrm{e}$ 스포츠 대회 종목은 롤, 배그, 오버워치, 스타 등 이런 게임은 남성이 더 많이 하고, 좋아 하기 때문에 여성이 이런 게임을 플레이하고 대화를 할 때 이런 주제 를 이야기한다면 조금 신기하기도 하고 한편으로는 되게 반가운거 같습니다. (C) 
이러한 고정관념과 타자화는 여성 게이머의 활동을 왜곡 하거나 오해하여 비하하거나 언어폭력으로 신조어를 지속적 으로 만들어 내는 기제로 작동되고 있다. 여성 게이머의 수 가 적어 이들의 활동을 업신여기거나 적절히 무시하는 언어 가 게임 커뮤니티를 통해 확산되어도 이모티콘, 침묵 등으로 동감하고 있다. 나아가 차별적이고 혐오적인 여성 게이머 표 현이 온라인 세계에서 활용되는 것을 흔한 일상의 현상으로 보고 있다.

여자가 남자보다 게임을 못한다는 선입견이 있다보니 게임을 잘하는 사람이 나타나게 되면 의혹부터 먼저 제기하는 사람들이 많지요, 그 리고 여자보다 게임을 못하면 안 된다는 열등감이 커서 이런 경우가 많다고 봅니다. 그러다보니 남초 커뮤니티에서 대리 의혹을 제기하는 경우가 많고 사람들의 생각이 그쪽으로 굳어지는 것 같습니다. (F)

일반 유저들 사이에서는 그런 일이 많아요. 실제로 자주 벌어지는 일들이기에 ‘대리' 탔다고 여기죠. 커플끼리 게임하는 경우 남자친 구가 여자 친구랑 같이 게임하고 싶어서 여자 친구에게 게임을 알려 주면서... (팀플레이게임 때) 초보자인 여자 친구에 의해서 같은 팀 원들이 손해를 보는 경우가 생기죠 심지어 일부러 이런 것들을 악용 하는 여성유저들도 존재했구요. 최근에는 여성유저 수도 증가하고 게임을 잘하는 여성분도 엄청나게 많아져서 이 시선은 점점 줄어들 고 있어요. 아무래도 개인방송의 영향도 크다고 생각해요. (A)

그건 대리 사건이 많기 때문이라고 생각해요. 잘하면 증명 해내면 되는 거죠. 남자도 똑같아요. (B)

\section{강자의 성적 유희대상: 여성 게이머는 000 입니다}

디지털 게임에서 남성은 다수, 강자로서의 입장에 있으 면서 소수, 약자인 여성 게이머를 종종 성차별과 성희롱으 로 괴롭히는 대상으로 보는 경험을 확인하였다. $\mathrm{e}$ 스포츠선 수들은 여성 게이머 모두를 약자나 피해자로 보는 건 문제 가 있다고 보면서도 대부분 남성이 여성을 괴롭히는 현상 에는 동감하고 있다. 특히, 게임 실력에 대해 정당한 평가 나 인정보다는 다수인 남성이 여성을 성적인 대상으로 여 기면서 온라인상에 놀림감으로 보는 점이라는 경험을 갖고 있다.

스칼렛, 엘리스 등 유저명을 보고 여성 게이머일 것 같으면 이미 느 긋하게 여기고 게임을 같이하는 팀일지라도 우습게 보는 경우가 있 어요. 가령, '살살 해줄테니 아파하지 마' 라고 하는거죠. 그냥 이런
말을 하면 될까 생각하고 말한다기 보다 게임이 워낙 빨리 진행되

니까 여성은 아예 제쳐두는 거죠. (A)

“나랑 사귈래요?” 라고 말하는 것도 봤어요. (E)

여성의 외모나 음성을 통해 성희롱 발언이나 비하하는 단 어가 포함된 용어를 흔히 쓰고 있다. 특히, 여성의 반응이 없 거나 소극적이면 그 강도는 더 세지면서 게임 시 채팅창에서 성추행을 일삼거나 사설방을 만들어서 다시 만나자고 하는 등의 행위로 나타나고 있다.

채팅창에 여성에게 욕하는 걸 봤어요. 그랬더니 여성이 바로 퇴장하 더군요. $(H)$

$\mathrm{e}$ 스포츠선수들은 성적 괴롭힘을 목격했을 때, 함께 게임 하고 있던 친구들이나 다른 게이머들에게 공유하면서 여성 게이머에 대한 추행을 더 많은 남성 주변인들이 즐기고 있는 경우도 있다. 이렇게 집단적으로 유포하면서 여성 게이머들 이 혹시라도 피해자로서 항의나 대응하지 못하도록 억압하 는 등의 모습을 보이는 강자의 힘이 여성들의 심리를 무력하 게 만드는 요소로서 경험하게끔 만든다. 게임에서 성적 괴 롭힘 피해 경험을 한 여성 유저들이 겪는 심리적 고통은 충 격, 불안, 분노, 우울, 억울함, 소외감 등 복합적이며 오랜 시 간동안 피해 경험에 대한 생각으로 일상생활에 피해를 가져 온다는 점을 조사한(Kim, 2019) 것처럼 유희의 대상으로 여성 게이머가 받은 성희롱과 혐오는 심각하다. 게임을 좋 아하는 여성 게이머들의 접근을 성희롱이나 혐오를 통해 디 지털 세계의 '장애물'로서 남성을 인식하게 하는 잠재적 위 험 또한 갖고 있다.

캐릭터 목소리가 여성으로 확인된 게이머는 직접적인 성차별의 피 해자로 볼 수 있다고 생각해요. 욕을 바로 내뱉어요. 게임에 지고 있 거나 경쟁이 치열해질 때 여성 유저에게 심한 욕을 더 많이 하는 것 같아요. (E)

Maeng et al.(2018)은 온라인 게임 내 성차별 실태 조사 연구에서 여성 유저들이 가해자(남성)와 같은 방식으로 욕 설이나 성희롱 등으로 되갚아주며 대응하는 방식으로 인해 가해자와 같은 부류의 사람으로 간주되는 우려를 인지하면 서도 당시의 감정적 모욕감을 해결하기 위한 방법이 없음을 문제 삼아, 폭언과 성희롱 가해자에게 적극적인 제재 시스 
템이 필요하다고 제안하였다. 현재 사이버 폭력과 성추행에 대한 신고시스템이 정부기관이나 eSport협회에 마련되어 있지만 이 시스템의 처리과정이 공개되지 않고 처벌수위가 낮다는 생각에 피해자들의 활용은 미미한 형편이다.

\section{여성 게이머를 대하는 태도가 전환되어야겠지요}

여성 게이머는 아기자기하고 쉬운 게임을 선호하며 게임 의 숙련도가 낮을 것이라는 고정관념을 갖고 한국남여 청년 게이머의 게임 취향을 연구했다는 연구자 고백을 남긴 Song et al.(2017)의 연구는 남성들의 여성 게이머에 대한 젠더 태도를 단적으로 보여주고 있다. 남성 $\mathrm{e}$ 스포츠선수들도 여 성 게이머의 수가 적다는 이유로 함부로 하는 것을 경험했으 며, 이를 개선하기 위해서는 여성에 대한 태도가 전환될 필 요가 있다고 말한다.

같이 해본적도 없는데 (잘하는 여성 선수에게) 대리 의혹을 하는 건 잘못됐다고 생각합니다. 같이했는데 잘하면 $\mathrm{e}$ 스포츠에 재능이 있 고 좋아하는 게임을 하시는 분이라 생각합니다. 그런 분들도 분명 있을 것입니다. $(G)$

사람마다 재능 차이가 있지만 어차피 여자나 남자나 같은 사람이기 에 똑같은 시간을 주고 연습을 시키면 서로 실력이 비슷할 거에요. 남성 여성 구분할 것 없이 그 게임에 얼마나 많은 시간투자와 노력 을 했느냐에 따라 좋은 실력을 갖게 되는 것을 알고 있기에 여성유 저가 잘하는 것이 전혀 이상하지 않은데요. (D)

남성 선수들은 대부분 여성에 대한 편견과 의심이 여성이 게임을 못할 것이라는 가정을 지배적으로 하기 때문이라 여 긴다. 개인적인 견해로는 무조건적인 부정적 인식을 하지 않는 것으로 확인되었다. 또한 앞으로 $\mathrm{e}$ 스포츠의 변화와 발 전을 위해서는 게임을 좋아하는 여성도 남성과 마찬가지로 교육지원과 기업의 후원이 따르길 기대하고 있다. 이를 통 해 더 많은 여성들이 게임을 즐긴다면 남성 게이머에 대한 생각도 달라질 수 있다고 낙관한다. 나아가 그러한 전환이 e 스포츠가 강자와 약자로서 남성과 여성을 대비하는 것을 넘 어 함께 즐기는 장이 될 수 있다고 본다. $\mathrm{e}$ 스포츠선수들은 현재 자신의 위치에서 최선을 다하는 것이 $\mathrm{e}$ 스포츠의 사회 적 역할에 보탬이 된다고 하였다.

\section{결론}

스포츠는 사회 변화를 비춰주는 거울이자, 사회의 축소판 이다. 오랜 역사 속에서 스포츠는 '남성 중심 영역' 으로 분류 되어 왔다(Hong \& Lim, 2020; Kim \& Park, 2009). 그러 나 $\mathrm{e}$ 스포츠는 성별 구분이 없는 스포츠이고, 경쟁에서 요구 되는 신체적 기술 또한 성별에 따른 차이를 만들지 않는다 (Holden, Kaburakis, \& Tweedie, 2019). 그럼에도 불구 하고 프로로 활동하고 있는 여성 e스포츠선수는 매우 드물 다. 2021년 1월 현재, 한국e스포츠협회에 등록된 여자프로 선수는 0명이다. 〈Newzoo〉의 '2017년 e스포츠 시장 보고 서'에 의하면, e스포츠를 시청하는 여성 비율이 $39 \%$ 에 이른 다(Beak, 2017.12.26). 즉, e스포츠를 관람하고 시청하는 여성의 수는 많아지고 있다는 것이다. 팀이 원칙적으로는 남 녀로 구성될 수 있다는 사실에도 불구하고 $\mathrm{e}$ 스포츠는 심각 한 성별 불균형이 존재한다(Llorens, 2017). 현재 프로 팀과 아마추어 팀들은 남자로 구성되어 있으며 e스포츠 분야의 다양한 직업인 해설위원, 캐스터, 팀 소유자, 코치 등도 대부 분 남자로 구성되어 있다(Ji, 2019).

본 연구는 $\mathrm{e}$ 스포츠선수들의 젠더인식을 조사하고자 현재 프로팀에서 활동 중인 남성 $\mathrm{e}$ 스포츠선수 8명을 인터뷰하였 다. 그 결과 13 개의 내용과 3 개의 하위범주, 3 개의 상위범주 의 내용을 발견하였다. 상위범주는 여성게이머에 대한 성역 할 고정관념 재현, 각자의 성적 유희대상, $\mathrm{e}$ 스포츠계의 역할 이 도출 되었다. 먼저 $\mathrm{e}$ 스포츠선수의 간접경험을 통해 본 여 성 게이머에 대한 성역할 고정관념은 사회에서 인식하고 있 는 것과 큰 차이 없이 여성 게이머에 대한 부정적인 이미지를 갖고 있다. 연령이 낮은 선수는 좀 더 열린 사고방식을 갖고 있으며, 여성 게이머 수가 많아지면 e스포츠계도 여성에 대 한 긍정적인 인식을 갖게 될 것으로 기대하고 있다. 둘째, 여 성 게이머에 대한 욕설, 언어폭력을 지속적으로 일삼으며 비 속어를 생산하고 있으며, 나아가 여성 게이머에게 성추행을 행함으로써 게임 세계에서 여성을 점점 멀어지게 하는 괴롭 힘 현상이 나타나고 있다. 마지막으로, e스포츠계에 여성 프 로선수가 없는 현실적인 문제를 해결하기 위해서는 여성 게 이머가 많이 활동할 수 있는 통로가 제도적으로 마련될 수 있 기를 기대하고 있다. 이러한 e스포츠선수들의 젠더 인식을 근거로 e스포츠계 젠더 인식 변화를 위해 다음과 같이 제언 하고자 한다.

첫째, $\mathrm{e}$ 스포츠선수들의 성 역할 고정관념을 탈피하기 위 
한 교육이 학교교육에서 제공되어야 한다. $\mathrm{e}$ 스포츠선수들은 중·고등학교 시절 프로활동을 시작하는 경우가 많으므로 청 소년시기 교육경험이 중요하다. 그러므로 학교교육 및 체육 수업에서 기본적인 성인지교육과 양성평등, 인권교육 관련 내용을 다뤄줄 필요가 있다. 특히, 본 연구에서 살펴본 $\mathrm{e}$ 스포 츠에서 발생하고 있는 젠더관련 사건, 사고를 주제로 한 연령 대 별 체육이론 수업을 제공해야 할 것이다. 청소년기에 형성 된 디지털 리터러시가 성인이 되어서도 온라인 세계에서 유 저의 태도로 나타난다는 점을 인식한다면 체육수업에서 관련 된 내용을 교육해야 한다(Ahn, et al, 2019; Dilute, 2020).

둘째, e스포츠선수들의 젠더 인식변화를 위해서는 선수들 의 노력만으로는 불가능하기 때문에 e스포츠 협회 내에서 연 수교육 등 지속적인 교육서비스 제공과 관리가 필요하다. 한 국을 대표하고 있는 단체기관으로서 책무를 다해야 할 것이 다. e스포츠가 우리사회에서 인기가 있고 사용자 및 일반인 에게 관심 있는 건전한 여가문화로 자리 잡기 위해서는 개인 의 도덕성만으로 실현 불가능하다(Niebuhr, 2013). 스포츠 선수, 지도자, 심판, 프론트를 대상으로 스포츠윤리, 스포츠 인권, 도핑 교육 등의 소양교육이 이루어지고 있는 것처럼 e 스포츠 역시 각 직업군을 대상으로 그 특성을 파악하여 맞춤 형 교육 및 연수 프로그램을 지속적으로 제공해주어야 한다.

셋째, 인터뷰를 통해 드러났듯이 e스포츠선수들의 학력 은 대부분 중졸, 또는 고졸이다. 상대적으로 은퇴시기가 빠 르며, 하루 평균 훈련은 15 시간 이상인 것을 감안하였을 때 (Korea creative content agency, 2018), 선수들이 학업 의 소홀함을 느낄 수밖에 없는 환경이다. 최근에는 $\mathrm{e}$ 스포츠 관련 특성화고등학교(서울 디지텍 고등학교, 한국 게임 과학 고등학교, 아현 산업정보고등학교 등)들이 개교하고 있다. 따라서 $\mathrm{e}$ 스포츠선수들의 학업과 인식변화를 위해 $\mathrm{e}$ 스포츠 관련 특성화고등학교에서 체계적인 학교교육과정을 수립하 여 운영할 필요가 있다. 본 연구는 온라인 게임에서의 언어 성희롱을 근본적으로 해결하기 위해서는 사회적 인식전환을 위한 노력이 우선적으로 요구될 뿐 아니라 무엇보다도 학교 교육을 통해 풀어가야 한다고 주장한 Kim et al.(2020)의 연구에 동의하며 관련 학교 교육주체들의 노력이 절실히 필 요한 시점이다.

본 연구는 $\mathrm{e}$ 스포츠 젠더인식에 대해 남성 $\mathrm{e}$ 스포츠선수들 의 사례를 분석하였기 때문에 여성 e스포츠선수들의 젠더인 식에 대한 충분한 자료를 반영하지 못했다는 제한점을 갖고 있다. 또한 e스포츠가 혼자서 모니터를 보고 게임을 장시간
하므로 의사소통이 원활하지 않은 현실적 문제도 있었다. 선 수들은 직접 인터뷰 시 가벼운 대화나 자신의 의견을 말하는 데 부끄러워하거나 예/아니오를 묻는 질문이 아님에도 불구 하고 짧게 답하여 어려움이 많았다. 온라인상에서의 소통도 마찬가지였다. 이와 같은 어려움에도 불구하고 $\mathrm{e}$ 스포츠 프 로선수들의 목소리를 통해 e스포츠에서 지속적으로 발생하 고 있는 젠더문제에 대해 프로선수들의 인식이 어떠한지 주 목했다는 점에서 의미 있는 연구라고 볼 수 있다. $\mathrm{e}$ 스포츠는 양성평등의 잠재력이 매우 큰 스포츠이지만, 동시에 남성 지 배라는 전통적 역학이 불가피한 것처럼 보인다. 따라서 '왜 그런 것인가'를 살펴보는 것이 중요한 연구 과제가 될 것이 다. 프로 e스포츠 산업이 여성에게 적대적인가? 여성들은 e 스포츠의 기술 훈련과 향상에 시간들이기를 꺼려해서인가? 이와 같은 질문들은 e스포츠 젠더 장벽의 본질을 이해하기 위해 심층적으로 연구되어야 할 주제다. 또한 e스포츠계가 여성에게 보다 개방적인 환경으로 만들기 위해 제도적인 조 치를 취할지 여부 역시 고려할 가치가 있다. 본 논문은 $\mathrm{e}$ 스포 츠 젠더 연구의 유익한 소재가 되고 젠더 불균형 토론이 활발 해지는 데 도움이 될 것으로 기대한다.

\section{참고문헌}

Ahn, H. N., Choi, M. O., Kim, Y. S., \& Jung, N.S. (2019). Adolescents Motivation and Digital Literacy according to the Level of Internet Over-dependency. Journal of Learner-Centered Curriculum and Instruction, 19(6), 1345-1363.

Bang, H. K. \& Won, Y. J. (2015). Progamers" Labor : Postmodern Mode, Modern Ethics. Korean Journal of Communication \& Information, 74(6), 7-37.

Bayrak, E.A. (2020). Comparision of the attitudes towards learning with the participation motivation level in e-sports players. African Educational Research Journal, 8(1), 83-89.

Beak, C. 대기업은 왜 $e$ 스포츠 철수하나? (2017.12.26). The Kyunghyang Shinmun. Retrieved on January 23, 2021 from http://weekly.khan.co.kr/khnm.html?mode=view\&code $=115 \&$ artid $=201712191701351 \& \mathrm{pt}=\mathrm{nv}$

Brehm A. Navigating the feminine in massively multiplayer online games: Gender in world of Warcraft. Frontiers in psychology. 
2013;4:903. https://dx.doi.org/10.3389/fpsyg.2013.00903

Cunningham, G. B., Fairley, S., Ferkins, L., Kerwin, S., Lock, D., Shaw, S. \& Wicker, P. (2018). eSport: Construct specifications and implications for sport management. Sport Management Review, 21, 1-6.

Dilute(2020). I am a gamer: Woman. Paju: Dongnyuk.

Downfall of affect, 10 years history of Korean e-sports, Journal of Korea Game Society, 20(2), 61-74.

Gamers. The Korea Institute of Information and Communication Engineering, 21(1), 72-81.

Holden, J., Kaburakis, A., \& Tweedie, J. (2019). Virtue(al) Games: Real Drugs. Sport, Ethics and Philosophy, 13(1), 19-32.

Hong, J, E. \& Lim, B. C. (2020). Gender Typing of Sports: Korean College Students' Perception of Gender Stereotype in Sports. Korean Journal of Sports Science 29(6), 71-82.

Ji, J. W. (2019). How did they become progamers? Seoul: Campue Mentor.

Ju, J. Y. \& Yoo, C. S. (2019). Analysis of eSports Experience: The Effect of Motivation and Experience on the Satisfaction and Behavioral Intention. Journal of consumer studies, 30(4), 261-281.

Kang, B. C. (2000). A study on Sports and Sexism. Research on liberal arts education. (5), 1-9.

Kim, D, H., Kim, S. H., Kim, S. L., Moon, H. Y., Park, J. W., \& Lee, S. H. H. (2020). The Influence of Sexual Discrimination in Online Game, Interpersonal Competence on Internalized Shame in Female College Students. The Journal of Kyungpook Nursing Science 23(1) 28-39.

Kim, J. H., \& Park, S. J. (2009). Sexual discrimination in sport. The Korean Journal of Physical Education 48(5) 25-33.

Kim, J, Y. (2019). Qualitative Study on Sexual Harassment in Digital Games: Applying the Grounded Theory. Korea Game Society, 19(6), 133-150.

Kim, J. Y. (2016.11.21). "年25\% 폭풍성장 e스포츠 성차별 뚜 렷...남자선수 수입 10배" Yonhapnews Retrieved on January 23, 2021 from https://www.yna.co.kr/view/ AKR20161121124600009.

Kim, J. \& Hwang J. Y. (2020). A Study on Esport Participation and Involvement of College Students: The Influence of Perception of Competitiveness, Gender, and
Athlete Status. Journal of Korean Association of Physical Education and Sport for Girls and Women 34(4), 17-38

Kim, K. H. et al. (2019). Exploratory Study on Countering Internet Hate Speech: Focusing on Case Study of Exposure to Internet Hate Speech and Experts. in-depth Interview. Korean Society of Contents Association, 20(2), 499-510.

Lee, H. J. \& Kim, Y. S. (2020). e-sports are sports. Philosophy of Movement, 28(1), 19-30.

Lee, S. H. \& Hwang, O. C. (2020). The Understanding of eSports' Phenomenon and Interdisciplinary Approach. Korean journal of physical education, 59(2), 19-32.

Lee, Y. B. (2020). Preliminary research on esports of Northeast Asia part 1: Downfall of affect, 10 years history of Korean e-sports. Journal of Korea Game Society, 20(2), 61-73.

Llorens, M. R. (2017). eSport Gaming: The Rise of a New Sports Practice. Sport, Ethics and Philosophy, 11(4), 464-476.

Maeng, W. J. (2018). Implications for the Design of Sexual Harassment Prevention System for Online Games. Proceedings of HCI Korea, 2018(1), 470-475.

Newzoo. (2021). Newzoo's Esports Trends to Watch in 2021. Retrieved January 24. 2021. https://newzoo.com/insights /articles/newzoos-esports-trends-to-watch-in-2021/

Newzoo. (2020). 2020 Global games market report. Retrieved December 28. 2020. https://newzoo.com/insights/trend-reports/ newzoo-global-games-market-report-2020-light-version/.

Niebuhr, R. (2013). Moral Mman and Immoral Society: A Study in Ethics and Politics. Louisville, KY: Westminster John Knox Press.

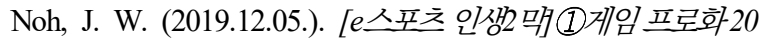
년...“은퇴 이후 설계 필요할 때” edaily. Retrieved on January 23, 2021 from https://www.edaily.co.kr/news/ read?newsId $=03844166622715568$

Park, S. J. (2020). Is Esport 'Real' Sport? Korean journal of physical education, 53(3), 47-58.

Park, S. J, Kim, J. H., \& Lim, D. Y. (2020). An ethical reflection on drug use in eSport, Korean Journal of Sport Science, 31(2), 306-317.

Seong, S. M. (2019.07.07.). 스타오버워차.LOL ... 여성 게이머 차별과혐오의시대. mediatoday. Retrieved on January 20, 
2021 from http://www.mediatoday.co.kr/news/articleView. html?idxno=201019

Song, D. H. (2017). Gender Differences and Gender Stereotype in Play Style among Young Korean Vitis L, Gilmour F. Dick pics on blast: A woman's resistance to online sexual harassment using humour, art and Instagram. crime, media, culture. An International Journal. 13(3), 335-355.

Yin, R. K. (2009). Case Study Research: Design and Methods (4th ed.). Thousand Oaks, CA: Sage.

Korea Creative Content Agency. (2017). Retrieved on January 19, 2021 from https://www.kocca.kr/cop/bbs/list/ B0000147.do? menuNo=201825

Korea esports-academy(2019). esports master plan. Goyang:
The Deeference.

KESPA http://www.e-sports.or.kr/ Retrived 27 January.2021

Kwonkim, H, Y. et al. (2020). feminism of the corona era.. Seoul: Humanist.

Kim, M. G. (2005.03.02.). $M B C$ 게임워 프라임리그' '경기조작' 파문. Retrieved on January 18, 2021 from Ohmynews, https://news.naver.com/main/read.nhn?mode=LSD\&mid=s ec\&sid1 $=105 \&$ oid $=047 \&$ aid $=0000059239$

Online issue team. (2014.03.31.). 피미르 천민기"한국인직원은 단 한명도 고용된 바 없다" Retrieved on January 15, 2021 from http://cm.asiae.co.kr/article/2014031314212189162 


\title{
$\mathrm{e}$ 스포츠선수의 젠더 인식 탐색
}

\author{
김진희 ${ }^{1}$, 임다연 ${ }^{2}$ \\ ${ }^{1}$ 안동대학교 교수 \\ ${ }^{2}$ 극동대학교 교수
}

[목적] 이 연구의 목적은 $\mathrm{e}$ 스포츠선수들의 젠더 인식을 조사하는데 있다. [방법] 참여자는 현재 $\mathrm{e}$ 스포츠 프로선수로 활동하고 있는 남성 프로게이머 8명을 목적표집과 눈덩이 표집을 활용하였다. 대면 및 비대면 인 터뷰로 자료를 수집하였으며 내용분석과 분류분석으로 분석하였다. [결과] $\mathrm{e}$ 스포츠선수들은 여성 게이머에 대한 간접적 경험을 설명해 주었으며 연구결과는 첫째, 여성 게이머에게 보편적으로 형성된 부정적인 약자로 서의 낙인 이미지를 갖고 있으며 이것이 디지털 게임에서 여성 게이머에 대한 성역할 고정관념을 지속적으로 재현하고 있는 기제다. 둘째, 남성들은 게임 세계에서 여성 게이머에게 욕설과 언어폭력, 성추행을 일삼고 있 으며 이는 강자의 입장에서 여성 게이머를 성적 유희대상으로 보고 있다. 셋째, 남성 e스포츠선수들은 연령에 따라 젠더 관련 인식이 보수적이거나 긍정적인 특징을 갖고 있다. 현재까지는 남성들의 주류 세계인 e스포츠 이지만 젠더와 성인지 교육을 통해 여성에 대한 태도 전환을 기대하고 있다. [결론] e스포츠계의 젠더 인식 변화를 위해서는 $\mathrm{e}$ 스포츠선수의 젠더인식에 대한 심층적인 이해가 필요하다. $\mathrm{e}$ 스포츠는 양성평등의 잠재력이 큰 스포츠이지만, 남성 지배라는 전통적 역학이 현재까지 이어지고 있는 현실에 놓여 있다. 따라서 '왜 그런 것인가'를 살펴보는 것이 후속연구로 수행되어야 한다. 본 논문은 e스포츠 젠더 연구 활성화에 학문적 관심을 불러일으키는 데 도움이 될 것으로 기대한다.

주요어: e스포츠, 젠더 인식, 고정관념, 성희롱, 젠더 평등 